\title{
Erratum to: Genetic diversity of Patellifolia patellaris from the Iberian Peninsula, a crop wild relative of cultivated beets
}

\author{
Lothar Frese • Lorenz Bülow • Marion Nachtigall • María Luisa Rubio Teso • \\ Maria Cristina Duarte $\cdot$ Elena Rey $\cdot$ José María Iriondo Alegría
}

Published online: 31 August 2017

(C) Springer Science+Business Media B.V. 2017

\section{Erratum to: Euphytica (2017) 213:187 DOI 10.1007/s10681-017-1942-0}

Due to an unfortunate turn of events during article processing data in Table 3 was given incorrect. Please find in this erratum the correct version of Table 3 that should be regarded as final version by the reader.

The online version of the original article can be found under doi:10.1007/s10681-017-1942-0.

L. Frese $(\bowtie) \cdot$ L. Bülow · M. Nachtigall · E. Rey Institute for Breeding Research on Agricultural Crops, Julius Kühn-Institut, Federal Research Centre for Cultivated Plants (JKI), Erwin-Baur-Str. 27,

06484 Quedlinburg, Germany

e-mail: lothar.frese@julius-kuehn.de

M. L. Rubio Teso · J. M. Iriondo Alegría Área de Biodiversidad y Conservación, Universidad Rey Juan Carlos, 28933 Mostoles, Madrid, Spain

M. C. Duarte

Centre for Ecology, Evolution and Environmental Changes (CE3C), Faculdade de Ciências, Universidade de Lisboa, Campo Grande, 1749-016 Lisbon, Portugal 


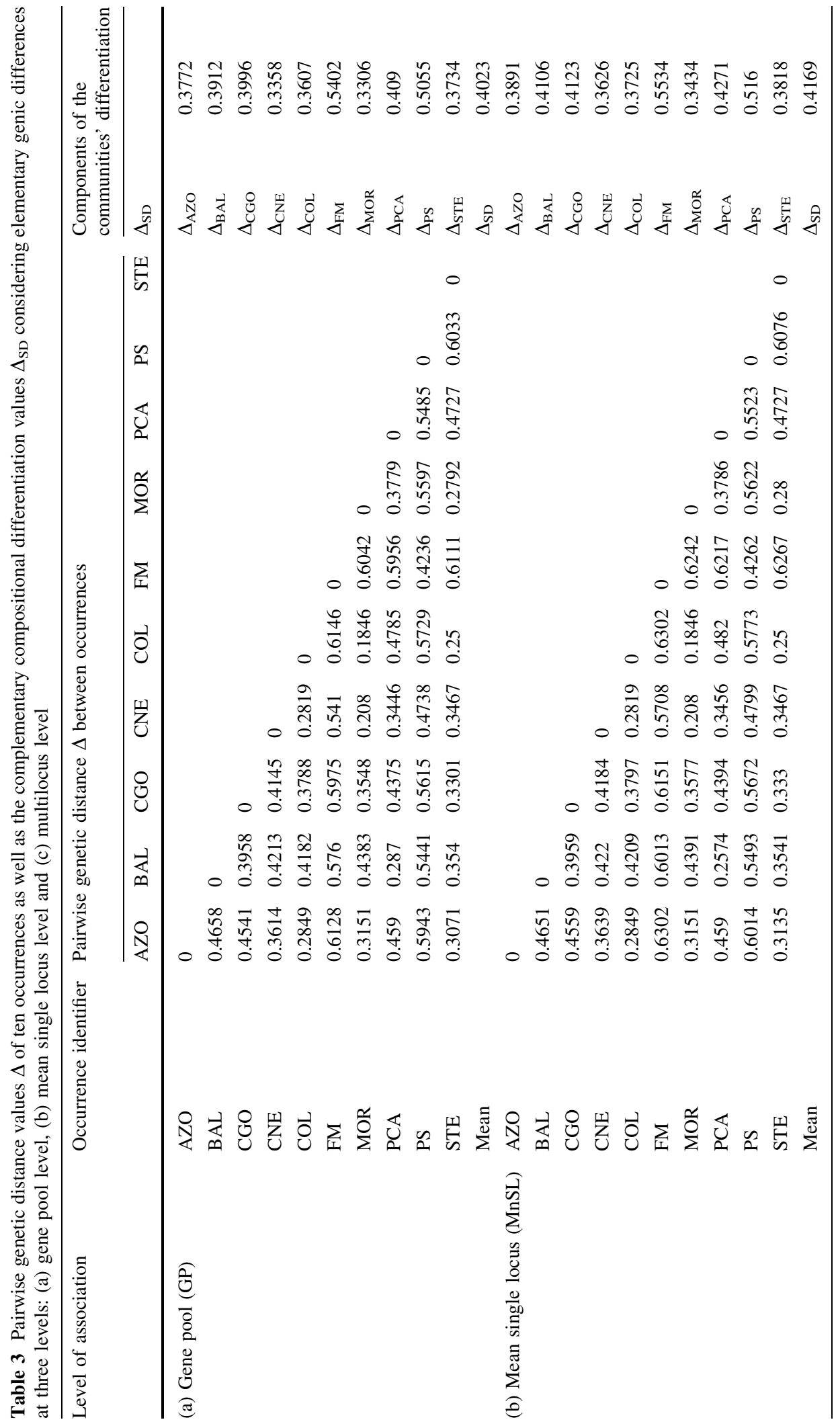




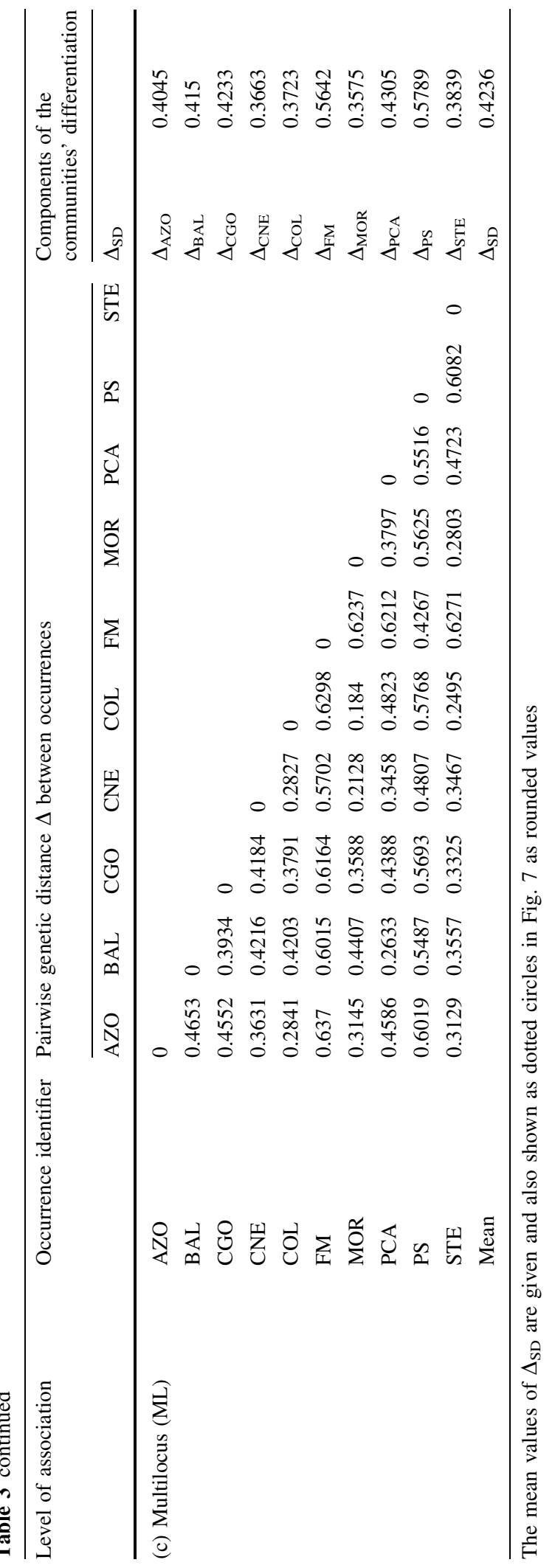

